\title{
INSERÇÃO LEXICAL OU ENVOLTÓRIO LEXICAL?
}

\author{
Miriam LEMLE* \\ Isabella Lopes PEDERNEIRA**
}

- RESUMO: Na análise comparativa das estruturas argumentais de verbos observadas no seu puro esqueleto, a semelhança entre diferentes línguas predomina. Contudo, ao se focalizarem verbos cognatos individuais resultam desencontros: para verbos com o mesmo rótulo fonológico, há estruturas que uma língua aproveita e a outra não. A explicação dessa falta de identidade no espelhamento precisa provir da leitura sintaticamente contextualizada da raiz: os falantes de diferentes línguas podem optar por diferentes leituras para as mesmas formas fonológicas nos mesmos contextos. Podem também dar rótulos fonológicos diferentes para 'os mesmos eventos' no mundo. Neste artigo pretendemos ilustrar dois fenômenos de interface sintaxe-semântica: a falta de isomorfia perfeita entre estruturas sintáticas e a sua leitura, com dados de reanálises de particípios, sufixos e prefixos; e realocações de raízes em contextos sintáticos de verbos. A razão de ser da imperfeição na correspondência sintaxe-semântica está no fato de que a estrutura sintática não é determinada por saberes extralinguísticos.

- PALAVRAS-CHAVE: Interface sintaxe-semântica. Esqueletos básicos de verbos. Ressegmentação na diacronia. Verbos cognatos italiano-português. Relações entre raízes e estruturas.

\section{Introdução}

Na interface entre a sintaxe e a semântica, todas as vertentes modernas da Gramática Gerativa fazem uso da expressão inserção lexical para caracterizar, na derivação sintática, a operação de implementação lexical da estrutura (CHOMSKY, 1965; HALLE; MARANTZ, 1993).

Consideramos que a ideia de que a gramática é um saber que tem lugar na mente dos falantes seja essencial, e a maneira pela qual chega a formar-se é o processo de aquisição. Assim, todas as questões linguísticas devem poder ser relacionadas a questões de aquisição e representação mental da cognição de linguagem.

\footnotetext{
* UFRJ - Universidade Federal do Rio de Janeiro. Rio de Janeiro - RJ - Brasil. 21941-901 - miriamlemle@gmail. com

** UFRJ - Universidade Federal do Rio de Janeiro. Rio de Janeiro - RJ - Brasil. 21941-901 - spederneira@hotmail. com
} 
Nessa perspectiva, que previsão corresponde ao termo inserção lexical na visão da interface sintaxe-semântica? Essa expressão produz uma metáfora entre recipiente e conteúdo: a estrutura sintática é isomórfica à segmentação do significado. E a leitura semântica da estrutura sintática já preenchida deveria ser normalmente composicional. A criança em fase de aquisição tenderia a dar leitura composicional a todos os elementos compostos.

Essa previsão de composicionalidade é satisfatória em muitos casos, tanto na sintaxe, quanto na morfologia derivacional. Para dar alguns exemplos, o ditado uma imagem vale por mil palavras é uma sentença que precisa ser interpretada literalmente para apresentar a disputa entre imagens e palavras; tristeza, numeroso e pensamento são palavras que serão automaticamente compreendidas por uma criança que já tenha adquirido conhecimento do significado de triste, número e pensar e também já possua o conhecimento das operações semânticas a serem feitas quando os sufixos -eza, -oso e -mento são respectivamente juntados aos nomes triste e número, e ao verbo pensar.

Porém, nos compostos, essa previsão falha tão repetidamente que é preciso que a teoria leve em consideração a normalidade dessa falha. Nosso propósito neste artigo é chamar a atenção para fenômenos de perda da composicionalidade semântica e mostrar que, para compreender o que é a variação e a mudança linguística, é necessário dar a devida importância à rearbitrarização de significados e descrever acuradamente os contextos sintáticos em que ela pode incidir, sem jamais perder o foco primordial na ligação com eventos mentais de saber linguístico.

Tomemos expressões idiomáticas da dimensão de sintagmas e sentenças:

Pé de chinelo é uma expressão irônica usada para fazer referência a pessoas que querem fazer-se passar por mais do que realmente são. O toque maldoso que provém de se atribuir essa qualidade a uma pessoa passa muito além da mera interpretação composicional do sintagma 'pé de chinelo', pois passa pelo pensamento do contraste entre a humildade de uma pessoa que habitualmente calça chinelo e a ambição social da pessoa assim rotulada. O significado menos prezador pode ser atingido em bloco, sem que necessariamente o falante-ouvinte compute composicionalmente a expressão.

Ovo de Colombo significa 'uma ótima ideia extremamente óbvia, porém possível de passar despercebida'. Esse significado provém de um suposto desafio proposto pelo rei da Espanha a Cristóvão Colombo, que o venceu fazendo um ovo (cozido!) ficar em pé, pressionando ligeiramente a casca contra a mesa. Não é indispensável conhecer o episódio que deu origem a esse modo de dizer para usá-lo adequadamente. 
Picar a mula quer dizer "sair às pressas", com base no ato feito pelo ginete de dar pequenas chicotadas no equino para fazê-lo acelerar o passo, sendo que a maioria das pessoas usa essa expressão sem sequer pensar em equinos.

Nos três exemplos acima, há um passo entre a leitura semântica composicional da expressão e sua leitura idiomática que não é linguisticamente previsível: o caminho de pensamento que une 'um pé portando chinelo' a 'uma pessoa injustificadamente petulante' não é um caminho linguístico, assim como não é linguístico o caminho entre a interpretação literal de ovo de Colombo e a leitura da expressão idiomática. O mesmo vale para qualquer outra expressão idiomática. Somos obrigados a responder à seguinte pergunta: por que é possível uma estrutura sintática receber uma leitura semântica que não é sintaticamente previsível? A resposta linguística é a de que, sendo a arbitrariedade saussureana uma forma de leitura permitida, pode ser reaplicada sobre construções (MARANTZ, 2001). De que maneira essa resposta é desenvolvida no modelo de gramática? O presente estudo dá um caminho para essa questão central na interface sintaxe-semântica.

O instrumento teórico dessa discussão é a Morfologia Distribuída. A característica essencial dessa teoria é que o léxico é decomposto de modo que, em vez de uma só lista, temos três listas: a lista A, cujos átomos são morfemas providos de significado funcional, porém desprovidos de forma fonológica; a lista B, cujos átomos são peças vocabulares com a informação de fonologia e traços gramaticais; e a lista C, denominada Enciclopédia, com a informação sobre a referência das peças de vocabulário e expressões idiomáticas. 
Figura 1 - Modelo de gramática da morfologia distribuída.

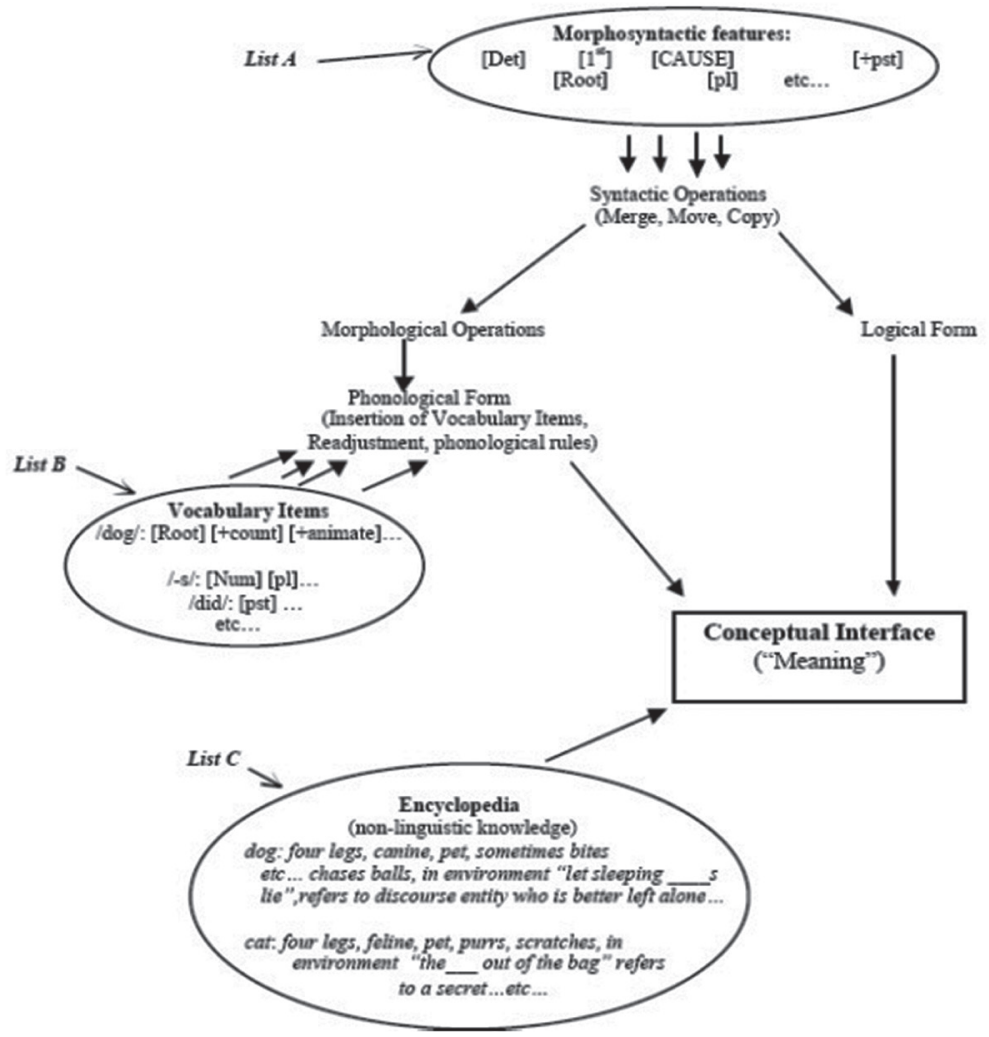

Fonte: Harley e Noyer (1999, p.2)

Nas próximas seções, mostraremos exemplos de rearbitrarização semântica recaindo no interior de palavras - particípio passado, palavras com sufixos e palavras com prefixos - e de sintagmas verbais - estrutura argumental. O objetivo a ser atendido por estes exemplos é o de ilustrar que a arbitrariedade entre forma e significado é uma convenção que acontece na mente de falantes-linguistas em todos os contextos sintáticos em que o seu módulo de gramática licencie essa arbitrariedade.

\section{Elos instáveis, porém inevitáveis}

Na diacronia do português, há um grande número de casos de verbos que são derivados de um particípio passado 'desgarrado', ou seja, uma forma que se encontra claramente desconectada semanticamente do verbo que era sua forma básica para gerações anteriores. 
O verbo arder provém do latim ardere, cujo particípio passado era arsus. Suponhamos que, por mudança fonológica, arsus tenha se transformado em assus, e, por isso, assus tenha deixado de ser computado como particípio passado de ardere, sem, porém cair em desuso, mas ganhando um novo uso: estado resultante de assare. Esse verbo assare é um verbo posterior a ardere e significa atingir o estado de cozido por assamento. Este novo verbo assare tem a sua própria leitura arbitrária. Esse passo nos faz ver que o elo entre arsus e ardere não é inviolável. De um salto, o adjetivo arsus, em sua nova pronúncia assus, passa a servir, para as crianças, de ponto de partida para a criação do verbo assare. Esse novo verbo, por sua vez, é linguisticamente obrigado a ter uma leitura arbitrária (PEDERNEIRA; LEMLE, 2009; PEDERNEIRA, 2010).

Quando assus deixa de ter leitura composicional a partir de ardere, temos a evidência de um elo instável. Se a forma assus pôde ganhar uma nova leitura, não mais ligada ao verbo ardere, aprendemos que uma nova relação arbitrária entre forma e significado pode ser convencionada por cada nova geração. Quando o verbo assare é formado a partir da nova leitura de assus, forma-se uma nova série computacional a partir do novo verbo assare. O mesmo esquema pendular entre leitura composicional e leitura arbitrária dos particípios passados pode ser descoberto em um grande número de mudanças diacrônicas na língua portuguesa.

\section{Quadro 1 - Composicionalidade, arbitrariedade e nova composicionalidade}

\begin{tabular}{|c|c|c|c|}
\hline $\begin{array}{l}\text { Forma } 1 \\
\text { Forma arbitrária de } \\
\text { base }\end{array}$ & $\begin{array}{l}\text { Forma } 2 \\
\text { Formação } \\
\text { composicional }\end{array}$ & $\begin{array}{l}\text { Forma } 3 \\
\text { Nova arbitrarização }\end{array}$ & $\begin{array}{l}\text { Forma } 4 \\
\text { Novas formações } \\
\text { composicionais }\end{array}$ \\
\hline ardere & arsus & assus & assare \\
\hline recipere & receptum & receptum & receptare \\
\hline concipere & conceptum & conceptum & conceptare \\
\hline volvere & voltus & voltus & voltare \\
\hline assumere & assumptus & assumptus & assuntare \\
\hline
\end{tabular}

Fonte: Elaboração própria.

No quadro 1, podemos ver que em todos esses exemplos, independentemente do tempo e do lugar onde o fato linguístico ocorreu, ele é sempre do mesmo tipo: os falantes de tempos mais antigos possuíam uma conexão gramatical entre o infinitivo verbal na Forma 1 e o seu particípio na Forma 2. Descendentes deles perceberam a Forma 2 como um adjetivo independente, com sua própria leitura 
saussureana, e criaram a Forma 3, desconectada do verbo na Forma 1. As pessoas cujo estado de saber linguístico contém as Formas da coluna 3 tomaram esse adjetivo como base para uma nova composição sintática, a Forma 4, autorizada por sua própria gramática: a formação deadjetival de verbos. Evidentemente são necessárias de duas a três gerações de falantes para acontecer toda essa sucessão de releituras.

É importante notar que, embora do ponto de vista etimológico seja sabido que as Formas das colunas 1 e 4 têm uma origem comum, não há paralelismo nas relações semânticas entre os verbos antigos e os verbos novos de cada um desses pares.

Considerando efeitos semânticos idiossincrásicos no uso de sufixos derivacionais, encontraremos outros casos semelhantes de 'rescisão de contrato' na derivação do significado da palavra derivada. Observem a relação semântica entre cana e caninha. Caninha é o diminutivo de cana, mas também é o nome da bebida alcoólica cachaça, derivada do caldo de cana. A noção de que a caninha é fabricada a partir da cana pode ser ignorada pelas pessoas que tomam o significado cachaça, sem incluir nele a noção de que caninha é álcool proveniente da cana.

Um caso formalmente semelhante, embora milenarmente distante, é o da palavra cadinho que provém do latim catinus (vasilha ou pote) que era um diminutivo de catus e, atualmente, significa 'vaso utilizado em operações químicas a temperaturas elevadas'. O leitor poderá constatar as semelhanças destes casos com estes outros na língua de hoje, como maçante, especial, rasura, viagem, triagem, originalmente formados a partir de, respectivamente, maça, espécie, raso, via e tri, relações estas que estão, para nós, totalmente perdidas. Mais uma vez, vemos que formações morfológicas com leitura composicional são relidas como formas com significado arbitrário.

Em que consiste essa pro-pens-ão (pender para frente) que as palavras complexas têm para perderem, de geração em geração de falantes, as suas leituras composicionais e caírem de volta para leituras arbitrárias, novas? O quadro 1 pode ser expandido com esses novos exemplos dos passos diacrônicos da descomposicionalização, rearbitrarização e, eventualmente, recomposicionalização das leituras pelo acréscimo de sufixos: 


\section{Quadro 2 - Composicionalidade, arbitrariedade \\ e nova composicionalidade}

\begin{tabular}{|l|l|l|l|}
\hline $\begin{array}{l}\text { Forma arbitrária } \\
\text { de base }\end{array}$ & $\begin{array}{l}\text { Formação } \\
\text { composicional }\end{array}$ & $\begin{array}{l}\text { Nova } \\
\text { arbitrarização }\end{array}$ & $\begin{array}{l}\text { Novas formações } \\
\text { composicionais }\end{array}$ \\
\hline cana & caninha & caninha/cachaça & \\
\hline catus & catinus & cadinho & \\
\hline maça & maçante & maçante/chato & \\
\hline espécie & especial & especial/incomum & especializar \\
\hline radere & raso & rasura & rasurar \\
\hline via & viagem & viagem/ \\
deslocamento & viajar \\
\hline tri & triagem & triagem/seleção & \\
\hline
\end{tabular}

Fonte: Elaboração própria.

Note-se que há várias maneiras para esse tipo de mudança acontecer. Por exemplo, na palavra caninha, nós temos, no mesmo momento do tempo, as leituras composicional e arbitrária de 'cana pequena' e de 'cachaça'. Já em cadinho (vaso usado para fundir metais), nós, hoje, não temos nenhuma lembrança da palavra que significava 'vasilha ou pote'.

O caso de maçante é semelhante. Poucas pessoas sabem o que é uma maça - 'uma forma mais aprimorada de porrete, arma de mão, forte e pesada'. $O$ adjetivo maçante foi inaugurado por pessoas que sabiam bem o que era uma maça, mas, para nós, não tem a menor importância não sabermos que coisa é, pois o adjetivo maçante está totalmente ressaussureanizado, e poderia servir de base para uma fala como: "esse diretor conseguiu maçantizar até mesmo o Chico Anísio."

Também há uma forte propensão para palavras compostas com prefixos serem relidas com a perda de sua conexão derivacional. Conecte-se, leitor, a seus próprios saberes de língua, para averiguar se tem consciência de que a palavra efeito se lê como ex feito - a partir do feito; arrasar como [[a ras]ar] - tornar raspado; despencar como [[des[penc]]ar] - cair de penca; aventura como [[ad [ven]it]ura] - coisas que estão por vir, acomodado como [[a[comod a]do]] para estado de cômoda indiferença.

Observemos outras palavras iniciadas por prefixos. O tipo de mudança que estamos observando aconteceu no passado e continua acontecendo. Tomemos 
o caso da palavra efeito. Ela provém de effectum, formado pelo prefixo exmais o particípio passado de facere. Sem dúvida houve uma geração na Roma antiga para a qual a palavra effectum significava 'a partir do feito'. Ainda entre falantes do latim, aconteceu a idiomatização -ressaussureanização- de effectum, que nós hoje herdamos já divorciado de facere. Porém a palavra efeito ainda implica semanticamente um fato anterior que causa o fato a que se refere à palavra efeito. $O$ derivado inicialmente composicional efetuar está para nós completamente descomposicionalizado em relação ao nome efeito e ao verbo fazer, e significa apenas 'fazer operações aritméticas ou realizar um pagamento'. Observações desse tipo sobre a interface entre a morfologia e a semântica lexical mostram que o estudo morfológico das famílias de palavras constitui evidências seguras de que existe uma ordem temporal necessária para a sequencialização da criação de palavras.

A propensão para a reanálise pode ser vista também a partir da precariedade surpreendente da nossa percepção da contribuição semântica dos prefixos. Basta perscrutar as páginas de um dicionário com palavras iniciadas por a-, de-, des-, com-, in-, pré-, re-, ob-, sub- e veremos que a nossa capacidade de reconhecer a contribuição do prefixo para o significado da frase é extremamente variável.

Tomemos o prefixo a-: alongar significa 'tornar longo', abreviar 'tornar breve', afinar 'tornar fino', aprontar 'fazer ficar pronto'; mas aprontar, intransitivo, significa 'fazer travessura' ou 'criar confusão'; adestrar não significa 'tornar destro', mas sim 'preparar um indivíduo para realizar uma ação com grande maestria'; arrumar já significou 'pôr no rumo certo', mas hoje em dia esse verbo 'perdeu o rumo', e significa 'pôr em ordem'. Arrombar não significa 'fazer ficar com rombo', mas sim 'abrir com violência'; aderir provém de adhaereo, composto com o verbo haereo, que significava 'ficar pegado a'; aludir tem a etimologia ad-ludere, e tinha originalmente o significado de 'gracejar a respeito de alguém', generalizado mais tarde para 'dizer algo a respeito de'. Nessa dezena de exemplos, temos um conjunto que vai desde a composicionalidade semântica transparente na concatenação entre o prefixo e um adjetivo ou nome bem conhecido (alongar, abreviar, afinar, aprontar) até a perda total da composição prefixo-raiz (aderir, aludir), passando pelo caso intermediário de arrumar e arrombar, em que a raiz é reconhecida nas palavras rumo e rombo, mas não existe uma regra regular de composição de significado correspondente à concatenação entre o prefixo e a raiz. Do ponto de vista teórico, os casos de arrumar/arrombar e aderir/aludir são idênticos: falantes deixaram de enxergar a composição sintática prefixo-raiz e por isso deixaram de aplicar a regra de leitura composicional no componente semântico (PEDERNEIRA, 2010). À distância de centenas de anos, diferentes grupos de falantes tiveram o mesmo 
tipo de comportamento linguístico: analisaram como uma só unidade morfológica uma sequência de fonemas que os seus ancestrais fatiavam morfologicamente como [prefixo+raiz].

Sobre o prefixo de-, podemos usar os exemplos depenar, denominar, debandar e degenerar como concatenações de prefixo e raiz com leitura composicional claramente perceptível: 'tirar as penas', 'atribuir nome', 'sair do bando' e 'afastar-se do gênero'. O caso de defenestrar é interessante, porque é fácil de ver que, em diferentes línguas, esse verbo recebe leitura de maneiras diferentes. Defenestrar tem leitura composicional em italiano e francês, porque nessas línguas janela diz-se finestra/fenêtre, mas em português os falantes não possuem em seu repertório de substantivos a palavra 'fenestra' para servir de base para a parte saussureana da leitura. Se as pessoas fazem leituras da pura estrutura com base apenas no reconhecimento do prefixo é uma questão que, por enquanto, está pendente. Os verbos deduzir e defender são semanticamente muito afastados dos verbos ducere (liderar) e fendere (impelir), inexistentes no português. O verbo derramar assemelha-se a este terceiro caso: provém de [de + ramar] que significava 'fazer ficar sem ramo'. O salto semântico para 'derramar líquido' é, por enquanto, um mistério.

Com o prefixo in- vamos considerar inicialmente os verbos inscrever, incriminar, infiltrar, nos quais provavelmente todos os falantes percebem as raízes $\sqrt{S C r e v-} \sqrt{ }$ crim- e $\sqrt{\text { filtr- }}$ e a relação semântica regular entre esses verbos e os significados de escrever, crime $e$ filtro. A seguir observemos implantar, inflamar e influir: aqui são visíveis as palavras planta, flama e fluir, porém a composição semântica do verbo prefixado não provém regularmente da combinação dos significados das partes. Finalmente em inflar, inchar, iniciar, implicar e imputar, a composição morfológica da origem etimológica está totalmente perdida, uma vez que 'flar', 'char', 'itus', 'plicar' e 'putar' são raízes completamente irreconhecíveis para falantes de português. Quanto à variação entre línguas, é interessante notar que impostar tem diferentes significados para falantes de português e italiano. Impostar a voz significa 'emitir corretamente a voz'; e impostar as mãos significa 'o ato de repousar as mãos sobre uma área sem encostá-las' em português; em italiano impostare una lettera significa 'colocar uma carta no correio' e impostare le pietre significa 'colocar as pedras em seus lugares'.

Reutilizando a mesma formatação dos quadros usados para descrever as rearbitrarizações de particípios e de palavras com sufixos, podemos resumir as observações feitas sobre palavras prefixadas. 


\section{Quadro 3 - Composicionalidade, arbitrariedade e nova composicionalidade}

\begin{tabular}{|c|c|c|c|}
\hline $\begin{array}{c}\text { Forma arbitrária } \\
\text { de base }\end{array}$ & $\begin{array}{c}\text { Formação } \\
\text { composicional }\end{array}$ & $\begin{array}{c}\text { Nova } \\
\text { arbitrarização }\end{array}$ & $\begin{array}{c}\text { Novas formações } \\
\text { composicionais }\end{array}$ \\
\hline longo & alongar & & \\
\hline breve & abreviar & & \\
\hline fino & afinar & afinar (ref. música) & desafinado \\
\hline pronto & aprontar & $\begin{array}{l}\text { aprontar } \\
\text { (travessura) }\end{array}$ & \\
\hline destro & adestrar & adestrar (treinar) & adestramento \\
\hline rombo & arrombar & arrombar (destruir) & arrombamento \\
\hline rumo & arrumar & arrumar & arrumação \\
\hline haerere & adhaerere & aderir & adesivo \\
\hline ludere & adludere (rir de) & aludir (mencionar) & alusão (menção) \\
\hline pena & depenar & depenar (roubar) & \\
\hline nome & denominar & & \\
\hline bando & debandar & & \\
\hline gênero & degenerar & degenerar (decair) & degenerado \\
\hline ramo & derramar(tirar ramo) & derramar (líquido) & derramamento \\
\hline ducere & deducere & deduzir & dedução \\
\hline fendere & defendere (impelir) & defender (favorecer) & defensor \\
\hline escrever & inscrever & inscrever(matricular) & inscrição (2) \\
\hline crime & incriminar & & \\
\hline filtro & infiltrar & infiltrar & \\
\hline planta & implantar & implantar & implantação \\
\hline flama & inflamar & inflamar & inflamação \\
\hline inflare & inflar & Inflar (moeda) & inflação \\
\hline inflare & inchar & inchar & \\
\hline plica & implicare & $\begin{array}{l}\text { implicar (desdobrar) } \\
\text { implicar (insistir) }\end{array}$ & $\begin{array}{l}\text { implicação } \\
\text { implicância }\end{array}$ \\
\hline putare & imputare & imputar & \\
\hline por & impor & $\begin{array}{l}\text { impostar (voz) } \\
\text { impostar (mãos) }\end{array}$ & \\
\hline
\end{tabular}

Fonte: Elaboração própria. 
Acabamos de ver três tipos de contextos sintáticos em que uma leitura composicional de um composto sintático se converte em uma nova leitura, não composicional.

Em que lugar da gramática acontece essa conversão de leitura? Na parte da gramática que é responsável pela produção de phrase structure, ou seja, a concatenação dos elementos da lista A e a posterior inserção das peças de vocabulário na estrutura final de cada fase da computação. O aprendiz que deixa de perceber uma fronteira morfológica acaba postulando uma nova peça de vocabulário e uma nova leitura. Essa nova leitura, depois de tornada arbitrária, adquire o direito de, recombinada com outros morfemas funcionais, expressar um novo significado arbitrário que pode não ter nenhum compromisso de corresponder de maneira regular com o primeiro significado arbitrário.

Esse conjunto de observações evidencia que palavras aparentemente complexas e que, como tal, deveriam ter a sua leitura obtida composicionalmente, podem ganhar novas leituras arbitrárias. Essas novas leituras relacionam-se com as leituras composicionais originais por caminhos semânticos que não são computações gramaticais, embora obedeçam a restrições gramaticais, como, por exemplo, as correspondências entre tipo de categoria e tipos de significado. Esses saltos semânticos, produtos da mente, imprevisíveis a partir da pura estrutura sintática, são responsáveis por grande parte das diferenças que separam as línguas românicas uma da outra.

A seguir, veremos assimetrias semânticas no estudo comparativo de estrutura argumental de verbos em duas línguas parentes: italiano e português. A semelhança entre os dois casos é a seguinte: um número finito e pequeno de estruturas sintáticas sustenta as limitadas possibilidades semânticas de todos os verbos de uma língua. Comparando verbos cognatos em português e italiano, estamos constatando que o compartilhamento das formas fonológicas não é um bom previsor do compartilhamento de leituras semânticas e, às vezes, nem de estruturas sintáticas. 


\section{A semântica da gramática envolta na da raiz}

Para as análises sintáticas dos verbos, assumiremos os seis tipos de estruturas sintáticas propostas por Marantz (2005, p.1-3) a partir dos quais, com pequenos acréscimos sintáticos de agente, por exemplo, é possível descrever todos os contextos funcionais que são os alicerces sintáticos da estrutura argumental possível, universalmente, por hipótese:

a.

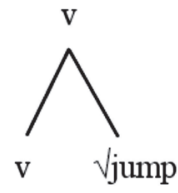

c.

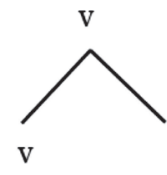<smiles>C[14CH]C</smiles>

the door

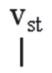

open

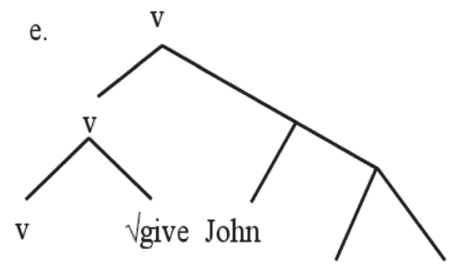

appl a book

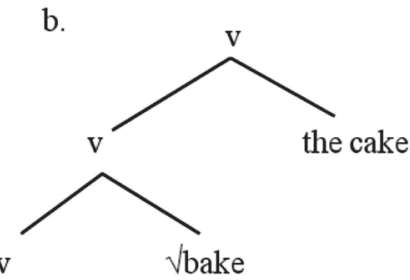

d.

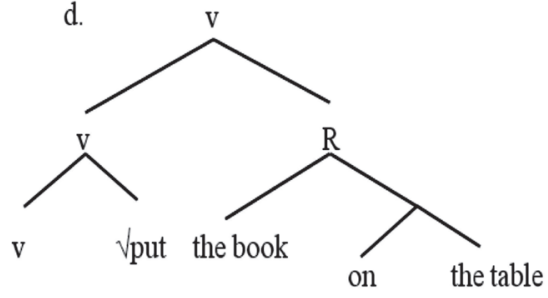

f.

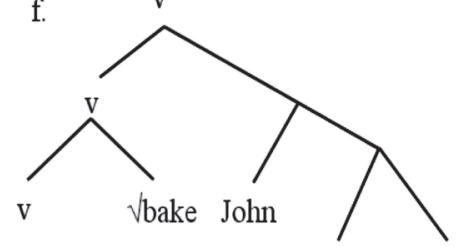

appl a cake

A estrutura (a) abarca verbos intransitivos com significado de criação, como, por exemplo, cantar, dançar, roncar, desenhar. A raiz é portadora de uma noção de 'maneira': 'agir cantando', 'agir desenhando'. A estrutura (b) é uma extensão da (a), onde o objeto direto é uma nominalização da raiz, ou um subtipo da maneira do evento apontado pela raiz: 'cantar uma canção', 'dançar um tango', 'desenhar uma girafa'. A estrutura (c) é a de verbos estativos que indicam estado final de um processo de mudança de 
estado, como abrir, ferver, derreter, esquentar. Esses verbos muitas vezes admitem um agente causador, e nesse caso a proposta é que outro morfema verbal introduza o agente, acrescentando o morfema do evento causativo acima do morfema estativo. A estrutura (d) é a de verbos de localização, o conjunto de location/locatum de Hale e Keyser (1993). Essa estrutura é mais uma variante da dos verbos de criação, pois o evento construído na raiz cria outra eventualidade, a localização de uma entidade em um lugar. As estruturas (e) e (f) são denominadas construções aplicativas: a estrutura (e) cria uma relação de posse pela qual se forma uma relação entre indivíduos, e a (f) cria uma relação entre um evento e uma entidade 'beneficiária' (ou 'maleficiária') como em 'elogiar alguém', ou 'caluniar alguém’. As línguas variam em termos do aproveitamento e exteriorizações morfológicas dos dois tipos de aplicativos (PYLKÄNNEN, 2000).

O que pretendemos fazer, a seguir, é analisar algumas estruturas argumentais de verbos cognatos em italiano e em português. O objetivo desse empreendimento é averiguar em que medida as duas línguas se assemelham no aproveitamento das estruturas sintáticas apresentadas acima e em que diferem nas leituras arbitrárias estruturalmente possíveis para as raízes cognatas.

\section{Variabilidade nas leituras semânticas}

Na observação da estrutura argumental do italiano, encontramos os seguintes contextos sintáticos em que a raiz $\sqrt{ }$ prend-pode aparecer:

(i.a) Voglio prendere in considerazione questa critica (quero levar essa crítica em consideração);

(i.b) Gli hanno preso la bicicleta (lhe pegaram a bicicleta)

(i.c) Da quel giorno, prese a odiarla (a partir daquele dia, começou a odiá-la)

(i.d) La casa ha preso fuoco (a casa pegou fogo)

(i.e) I carabinieri l'hanno preso (os guardas o pegaram)

O significado de prendere em italiano corresponde, grosso modo, ao português pegar.

A estrutura da frase (i.a) é o esqueleto (d) de Marantz. Neste caso, a palavra considerazione é o locativo da entidade questa critica. Considerazione é o lugar onde se coloca a critica, e a maneira de fazer isso é prendendo.

A estrutura sintática para o exemplo (i.d) é o caso (b) de Marantz, cuja estrutura $\left[\mathrm{DP}_{1}\left[\mathrm{VDP}_{2}\right]\right]$ é lida como verbo de criação com objeto direto do tipo DP 
tema incremental, e a leitura semântica é que se cria, prendendo (evento1), um evento 2, fogo. A estrutura sintática de (i.b) é formada a partir da estrutura (e) de Marantz e, por causa do aplicativo baixo, se faz uma relação entre bicicleta e $3^{\mathrm{a}} \mathrm{sg}$, sendo que o feixe [aplicativo $+3^{\mathrm{a}} \mathrm{sg}$ ] é implementado pelo pronome gli. A estrutura do exemplo (i.e) é a (c) de Marantz.

Em italiano, é possível prese a odiarla, onde odiarla é o estado de espírito tomado pelo DP sujeito de prendere. A estrutura sintática e a leitura de (i.c), portanto, serão as mesmas de (i.a).

Passando ao verbo prender na língua portuguesa, encontramos essencialmente as seguintes estruturas:

(ii.a) Juca prendeu o burro no poste

(ii.b) A polícia prendeu os marginais

(ii.c) Seus olhos verdes prendem corações

A estrutura sintática para o exemplo (ii.a) é a estrutura (d) do Marantz, e a leitura semântica é a criação, por meio de prender, de uma relação cujo evento é [DP [P DP]]. A estrutura sintática para (ii.b) é a estrutura (c) de Marantz, e a leitura semântica é a de que a polícia causou um estado tal que os marginais estejam presos. O exemplo (ii.c) é calcado no (ii.b): os olhos verdes causam um estado tal que os corações ficam presos, por type shifting da palavra coração em sentimento (PYLKKÄNEN; MCELREE, 2006).

No quadro abaixo, foram comparadas as duas línguas e foi constatado que o italiano apresenta a raiz $\sqrt{ }$ prend- nas estruturas (b), (c), (d) e (e), enquanto que o português somente nas estruturas (c) e (d). Contudo é importante perceber que nas duas construções utilizadas por ambas as línguas, (c) e (d), a leitura semântica não é igual. Em português, o estado final da coisa presa é irreversível, mas, em italiano, a ligação resultante de prendere é transitória.

As convenções formais no desenho dos quadros são as seguintes: na coluna da esquerda está a pura forma sintática e, nas outras duas, o italiano e o português, nessa ordem. O quadro mostra bem que a utilização de uma estrutura sintática pelas duas línguas não prevê a total semelhança semântica, mas apenas a parte da semântica estritamente derivada do esqueleto sintático. A notação 'xxxxx' significa o não aproveitamento da estrutura sintática por aquela língua. A semelhança entre os casos de estrutura argumental e os relativos à estrutura interna das palavras é a seguinte: a ausência de uso de uma estrutura sentencial corresponde à total perda da consciência dos prefixos e sufixos; a distinção idiomática entre as duas línguas para uma mesma estrutura corresponde às diferenças de uso de impostar impostare. 
Quadro 4 - Contextos sintáticos da raiz $\sqrt{ }$ prend-

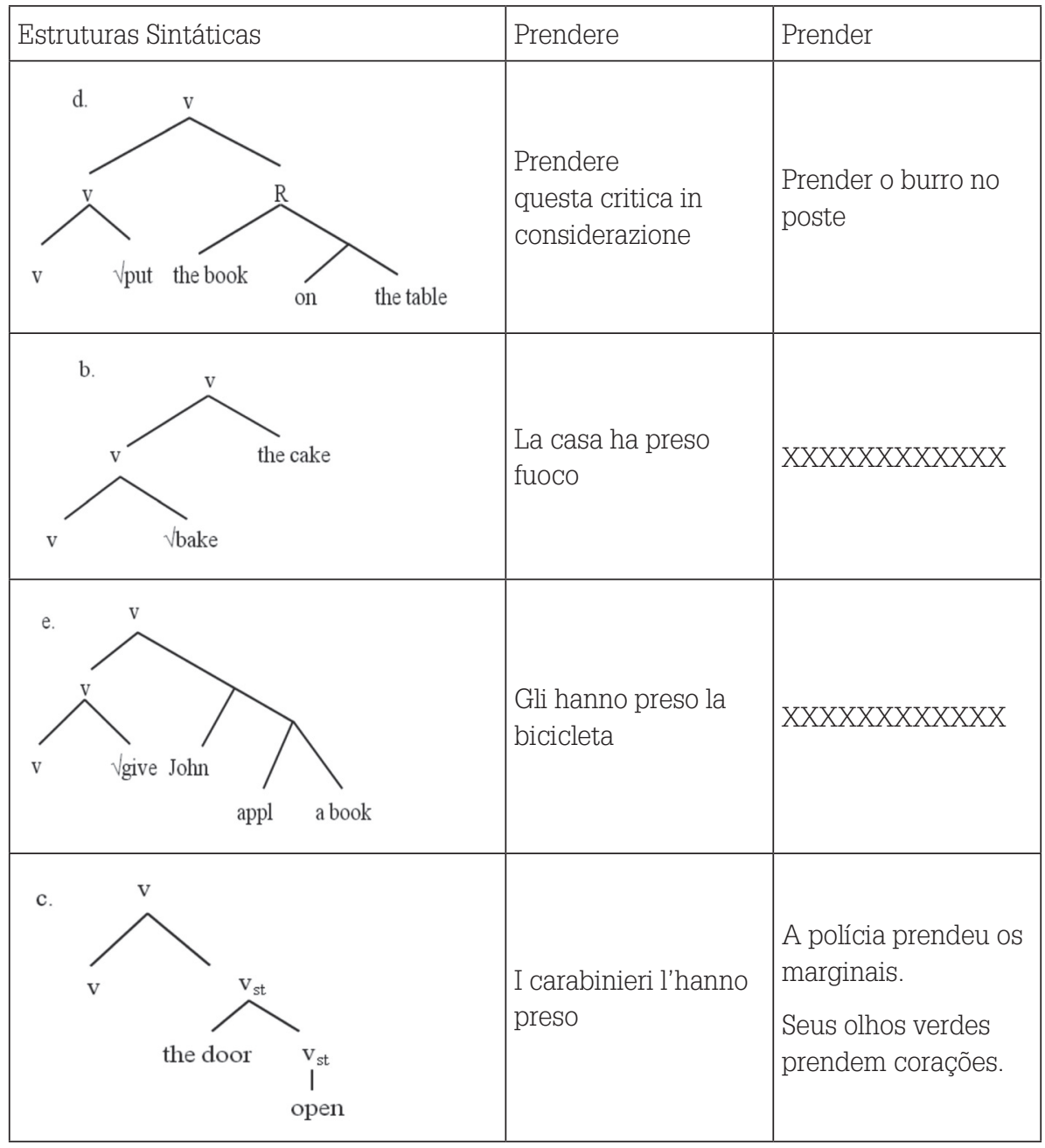

Fonte: Elaboração própria.

Resumindo os achados dessa comparação: os verbos cognatos de raiz $\downarrow$ prendcompartilham o uso das estruturas sintáticas (d) e (c), com as leituras semânticas do verbo em uma e outra língua divergindo em termos do aspecto. Somente o italiano faz uso das estruturas (b) e (e) com a raiz $\sqrt{ }$ prend-.

(iii.a) Ela ordenou os talheres na gaveta do bufê.

(iii.b) $\mathrm{O}$ general ordenou o contra-ataque.

(iii.c) O Papa ordenou muitos bispos. 
O verbo ordenar é sensível à polissemia do nome ordem: (i) ordem 'distribuição regular de objetos no espaço físico'; (ii) ordem - 'ato de fala em que a pessoa dotada de autoridade emite um comando' (destinado a criar ordem); (iii) ordem - 'organização religiosa'. O verbo ordenar significa 'pôr em ordem' se o nome ordem faz referência à arrumação do espaço físico (iii.a); significa 'mandar' quando o DP objeto pode ser lido como evento (iii.b); e significa 'admitir alguém como membro de organização religiosa' quando o nome ordem faz referência a esse tipo de organização (iii.c). As estruturas sintáticas de (iii.a) e (iii.c) são iguais e correspondem ao esqueleto (d) de Marantz, enquanto que a sentença (iii.b) corresponde ao esqueleto (b).

É possível ser gerada um tipo de frase que seja ambígua entre as duas estruturas acima, como por exemplo:

(iii.d) Ela ordenou vários relatórios.

A ambiguidade de (iii.d) é consequência da possibilidade de interpretar relatório como documento, sendo, então, ordenar lido como' pôr relatórios em ordem' (iii.a); ou como 'dar um comando para a feitura de documento', como em (iii.b).

A seguir, damos cinco sentenças que tipificam as possibilidades sintáticas de ordinare em italiano:

(iv.a) Ordinare le tavole. (arrumar as mesas)

(iv.b) Il medico mi ha ordinato una purga. (o médico me receitou um purgante)

(iv.c) Ho ordinato una birra. (pedi uma cerveja)

(iv.d) Il vescovo decise di ordinare il giovane diacono Luca Seidita. (o bispo decidiu ordenar o jovem diácono Luca Seidita).

(iv.e) Hitler ha ordinato la ritirata delle sue truppe. (Hitler ordenou a retirada das tropas)

A mesma polissemia encontrada no nome ordem no português foi encontrada em ordine no italiano. O significado de 'arrumação de espaço físico' está presente na frase (iv.a); o de 'comando' em (iv.b), (iv.c) e (iv.e); e o de 'ordem religiosa' em (iv.d).

O significado do verbo ordinare em italiano se assemelha muito, dependendo do contexto, aos significados dos verbos arrumar, mandar, receitar e pedir em português. 
Quanto às estruturas sintáticas, a de (iv.a) e a de (iv.d) são (d); a de (iv.b) é a (f), estrutura de aplicativo alto; a de (iv.c) é a (e), estrutura de aplicativo baixo; e a estrutura de (iv.e) é a (b) de Marantz.

A comparação das duas línguas nos fornece correspondência nas estruturas (b) e (d). Só o italiano tem as estruturas de aplicativo alto e baixo:

\section{Quadro 5 - Contextos sintáticos da raiz Vordin-}

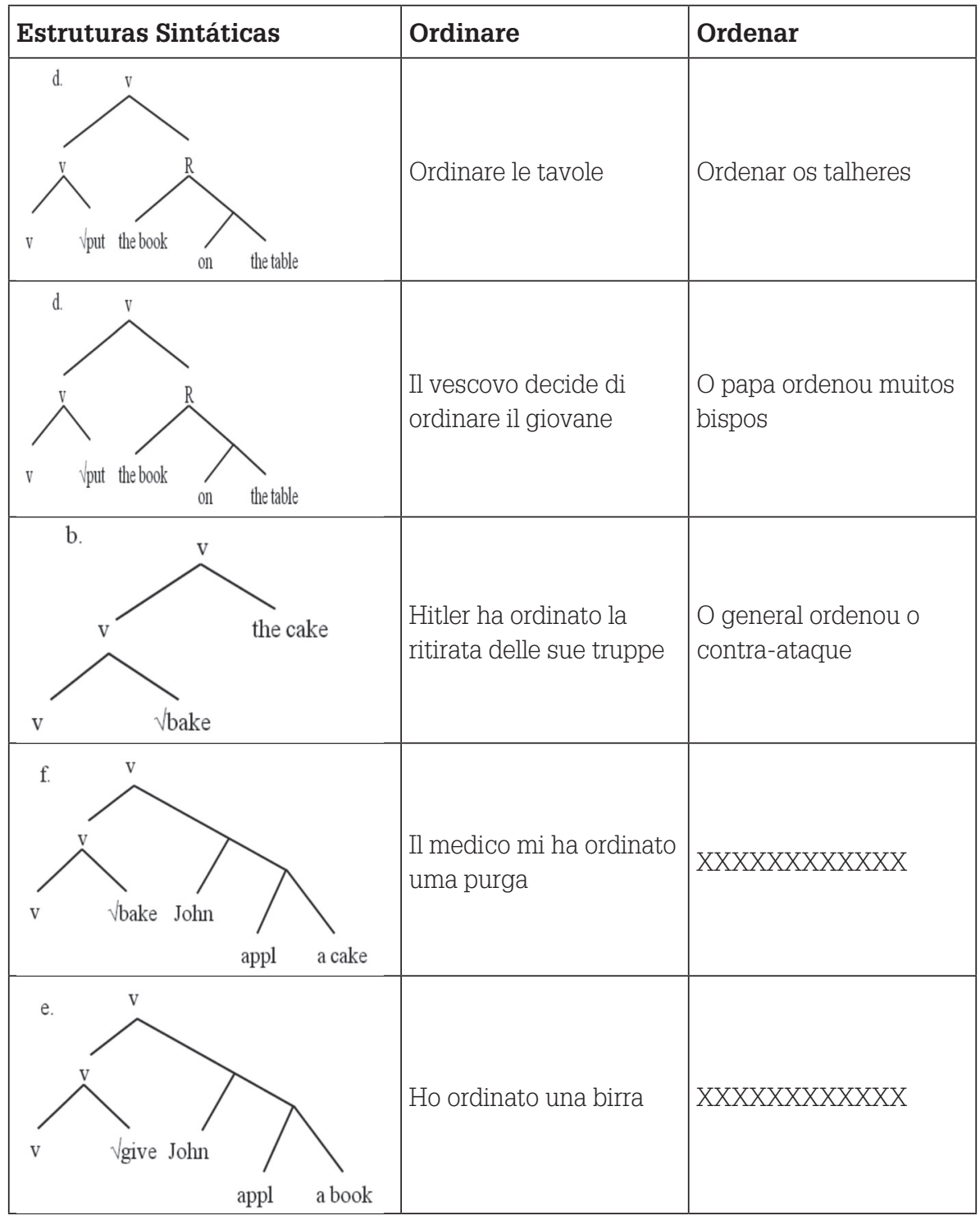

Fonte: Elaboração própria. 
Resumindo os achados: os usos da raiz Vordin- coincidem sintática e semanticamente nas duas línguas nos esqueletos (d) e (b), mas somente o italiano serve-se dos esqueletos (e) e (f), enquanto que o português, não.

Os verbos mancare e mancar têm como origem etimológica manicare, com a raiz manus. O verbete do italiano apresenta um conjunto de contextos sintáticos e de significados mais amplos do que o do português. Vejamos:

(v.a) I ragazzi sono mancati alla riunione. (os rapazes faltaram à reunião)

(v.b) Mi sono mancati dieci Euro per comprare quelle scarpe. (Faltaramme dez euros para comprar aqueles sapatos)

(v.c) Hai mancato di tatto. (te faltou tato)

Na sentença (v.a), estamos considerando a estrutura um caso do (c) de Marantz, em que o verbo mancare atribui um estado de faltoso ao seu sujeito, principalmente considerando que, em italiano, o emprego do auxiliar essere acarreta uma noção de estado. A sentença (v.b) assemelha-se a de (v.a), porém com o acréscimo do pronome mi, que é um aplicativo concatenado à estrutura sono mancati dieci Euro. O acréscimo de um aplicativo à estrutura estativa (c de Marantz) não consta do artigo Marantz (2005), mas é mencionado em Pylkännen (2000). Em (v.c), temos um caso de (d) com uma peculiaridade estranha: só é usado com sujeito de frase animado e o complemento de di é obrigatoriamente abstrato.

Em português, a única possibilidade estrutural é a de (a) cujo significado é que ele 'tem um defeito físico que compromete o seu andar'. Existe também o uso do tipo 'ele manca da perna direita', que, obviamente, provém da mesma estrutura que gera (v.b).

(vi.a) Ele manca.

É interessante notar que, para essa forma, o português e o italiano não compartilham nenhuma estrutura sintática. 
Quadro 6 - Contexto sintático da raiz $\sqrt{\text { manc- }}$

\begin{tabular}{|l|l|l|}
\hline Estruturas Sintáticas & Mancare & Mancar \\
\hline I ragazzi sono mancati alla & XXXXXXXXXXXX \\
riunione & $\begin{array}{l}\text { Mi sono mancati dieci Euro } \\
\text { per comprare le scarpe. }\end{array}$ & XXXXXXXXXXXX \\
\hline Hai mancato di tatto. & XXXXXXXXXXXX \\
\hline a. & Ex & Ele manca. \\
\hline
\end{tabular}

Fonte: Elaboração própria.

Para esse verbo, aconteceu um completo divórcio entre as duas línguas: o italiano usa para o verbo mancare, que significa 'faltar', as estruturas (c), (d) e (e); e o português usa a estrutura (a) e significa 'ter um andar trôpego causado por defeito na perna'.

Pela lógica, o significado de mancare em italiano - 'ter falta' - deve ter precedido historicamente o do português, já que é plausível o caminho de um aprendiz, na aquisição, ir de 'faltar' para 'faltar por razão de defeito na perna', mas a hipótese inversa é implausível.

Essa pequena amostra de análise de verbos cognatos, feita a partir das estruturas da sintaxe, nos permite ver que há muitos tipos de mapeamentos possíveis entre as duas línguas: pode haver entre os verbos cognatos subverbetes em que a sintaxe coincide e a semântica também; pode haver subverbetes com correspondência na sintaxe, mas diferença no invólucro conceptual; pode haver correspondência somente na fonologia, sem nenhuma correspondência nos esqueletos sintáticos. 
As diferenças de contextos de uso e significado dos verbos acontecem em que lugar da gramática? Neste caso, o lugar da gramática que está em ação, diferentemente do que vimos para a reanálise de particípios, sufixos e prefixos, é a interface entre a estrutura sintática e a sua leitura em Forma Lógica. Quando, para um determinado contexto de uso de um verbo, diferentes falantes atribuem a construção percebida a diferentes análises sintáticas ou semânticas subjacentes, a consequência é que eles criam um desencontro linguístico que nada mais é senão uma diferença paramétrica entre línguas.

Esse panorama favorece uma teoria em que a semântica ativada pela pura sintaxe e o invólucro semântico ativado pela raiz provenham de módulos distintos da gramática. Essa dissociação de módulos coloca a criança diante da necessidade de replicar na Forma Lógica, que é uma interface entre a Enciclopédia e a lista A, as mesmas opções escolhidas pelos seus predecessores, uma tarefa não muito fácil. Basta que algumas crianças se afastem de replicar as construções dos adultos, para que um subgrupo da comunidade apresente uma gramática alterada em relação aos mais velhos. A alteração está na combinação entre os invólucros (raízes) e os esqueletos. Apesar de tudo, essas "falhas pontuais" não mudam o conjunto universal dos esqueletos básicos da sintaxe.

\section{Conclusão}

As análises de palavras complexas e estrutura argumental nos levaram a explicar os dois conjuntos de mudanças linguísticas observadas por meio de desencontros gramaticais atribuídos a processos de aquisição.

No estudo das palavras complexas, constatamos que as diferenças entre línguas resultaram de reanálises que são consequência de diferentes maneiras de fazer os recortes de constituintes das palavras, que, por sua vez, resultam do não reconhecimento da parte lexical de peças de vocabulário. Essa parte é justamente a que não é inserida, pois é um apêndice acrescentado ao esqueleto sintático.

No estudo de estrutura argumental, as diferenças entre línguas resultam de desencontros entre falantes adultos e aprendizes na interface denominada Forma Lógica que se localiza entre a Enciclopédia e a lista A. A criança, por não conhecer bem a contribuição semântica da parte lexical do verbo, pode acabar por construí-lo na sua mente de maneira diferente à dos usuários adultos, ou pelo significado somente, ou mesmo pelo próprio reconhecimento da estrutura sintática. Mais uma vez, a responsabilidade principal pelas releituras reside na contribuição dos conceitos carregados pela raiz.

Em face do inegável efeito do reconhecimento semântico da raiz, gostaríamos de sugerir que, para raízes, o nome da operação inserção lexical seja substituído 
por envoltório lexical. Desse modo, estaremos dizendo que as posições do output da sintaxe precisarão ser envolvidas por uma peça vocabular que coincida em categoria gramatical com o que provém da sintaxe, mas não necessariamente satisfaça sempre as mesmas condições pragmáticas de uso.

LEMLE, M.; PEDERNEIRA, I. L. Lexical insertion or lexical wrapping? Alfa, São Paulo, v.56, n.2, p.469-490, 2012.

- ABSTRACT: When we focus on the pure skeletal structures of verbs, the predominant observation is interlanguage similarity. However, if we focus on individual verb cognates between related languages we find many cases of mismatch: verbs with the same phonological label are often used in different syntactic structures in these languages. The only explanation for these mismatches has to come from the syntactically contextualized reading of the root: speakers of different languages can opt for different readings for the same phonological forms in the same context, and they may also give different phonological labels to the 'same events' in the world. Our aim in this article is to show the lack of perfect isomorphism between syntactic structures and their readings with data of reanalysis of participles, suffixes and prefixes, and choice of different roots in verbal syntactic contexts. What causes the imperfect correspondence between syntax and semantics is the fact that syntactic structure is not determined by extralinguistic knowledge.

- KEYWORDS: SyntaX-semantic interface. Basic verb skeletal structures. Historical changes in morpheme segmentation. Italian-Portuguese cognate verbs. The readings of roots according to structures.

\section{REFERÊNCIAS}

CHOMSKY, N. Aspects of the theory of syntax. Cambridge: MIT, 1965.

HALE, K.; KEYSER, S. J. On argument structure and the lexical expression of grammatical relations. In: HALE, K.; KEYSER, S. J. (Org.). The view from Building 20: essays in honor of Sylvain Bromberger. Cambridge: MIT, 1993. p.53-109.

HALLE, M.; MARANTZ, A. Distributed morphology and the pieces of inflection. In: HALE, K.; KEYSER, S. J. (Org.). The view from Building 20: essays in honor of Sylvain Bromberger. Cambridge: MIT, 1993. p.111-176.

HARLEY, H.; NOYER, R. State-of-the-article: distributed morphology. GLOT International, [S.1], v.4, n.4, p.3-9, 1999.

MARANTZ,A. Words. 2001. Disponível em: <http://web.mit.edu/marantz/Public/ EALING/WordsWCCFL.pdf>. Acesso em: 10 set. 2005.

Rederived generalizations. 2005. Disponível em: <http://ealing.cognition. ens.fr/ealing2010/handouts/KoopmanReadings/MarantzReDeriving.pdf>. Acesso em: 5 ago. 2007. 
PEDERNEIRA, I. L. Etimologia e reanálise de palavras. 2010. 125f. Dissertação (Mestrado em Linguística) - Faculdade de Letras, Universidade Federal do Rio de Janeiro, Rio de Janeiro, 2010.

PEDERNEIRA, I. L.; LEMLE, M. Como criamos palavras novas: considerações sobre dois processos de reanálise. ReVEL, [S.1], v. 7, n.12, 9. p.1-14, 2009.

PYLKKÄNEN, L. What applicative heads apply to. 2000. Trabalho apresentado ao 24th Annual Penn Linguistics Colloquium, Philadelphia,2000.

PYLKKÄNEN, L.; MCELREE, B. The syntax-semantics interface: on-line composition of sentence meaning. In:TRAXLER, M.; GERNSBACHEr, M. A. (Ed.). Handbook of psycholinguistics. New York: Elsevier, 2006. p.537-577.

Recebido em 20 de setembro de 2011.

Aprovado em 20 de agosto de 2012. 